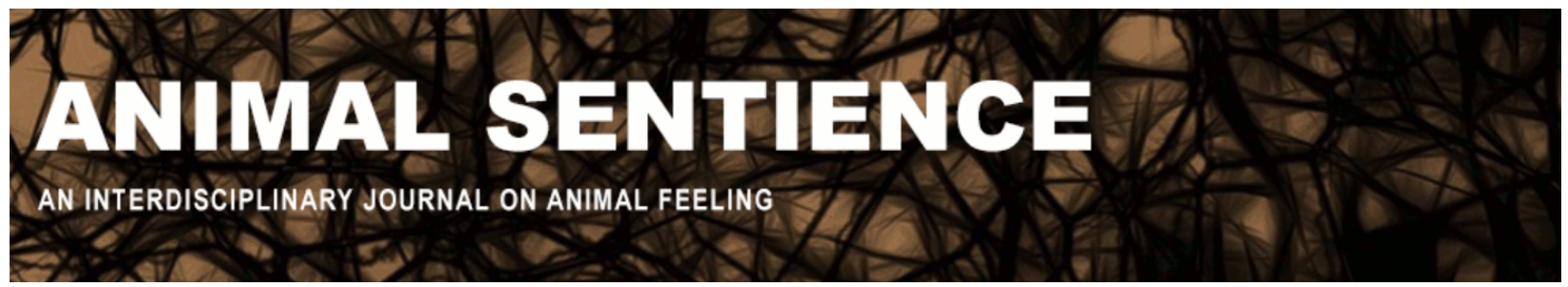

Broom, Donald M (2020) The necessity of human attitude change and methods of avoiding pandemics. Animal Sentience 30(7)

DOI: $10.51291 / 2377-7478.1634$

Date of submission: $2020-08-26$

Date of acceptance: $2020-08-26$

(c)

This article has appeared in the journal Animal

Sentience, a peer-reviewed journal on animal

cognition and feeling. It has been made open access,

free for all, by WellBeing International and deposited

in the WBI Studies Repository. For more information,

please contact

wbisr-info@wellbeingintl.org.

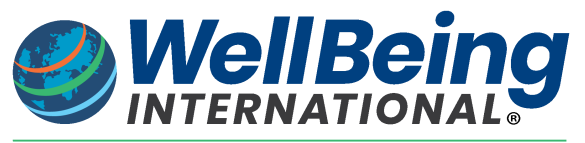

SOLUTIONS FOR PEOPLE, ANIMALS AND ENVIRONMENT 


\title{
The necessity of human attitude change and methods of avoiding pandemics
}

\author{
Commentary on Wiebers \& Feigin on Covid Crisis
}

\author{
D.M.Broom \\ Department of Veterinary Medicine, University of Cambridge
}

\begin{abstract}
Humans share their biology with other animals and in each of their actions should consider the consequences for all life. A series of measures can be taken by governments and individuals that would minimise inter-specific transfer of pathogens from wildlife and reduce the development of antimicrobial resistance.
\end{abstract}

Donald M. Broom is Emeritus Professor of Animal Welfare at Cambridge University, Department of Veterinary Medicine and St Catharine's College. His research concerns the scientific assessment of animal welfare, cognitive abilities of animals, ethics of animal usage and sustainable farming. Website

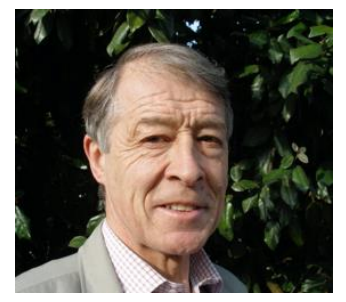

1. Humans and other life. Ideas about the role of humans in the world need major revision in order that all life can continue and flourish. Wiebers \& Feigin $(2020 a, b)$ (W\&F) draw attention to the possibility of learning from the COVID-19 crisis. Otherwise it is likely that humans will cause other pandemic diseases with wide-ranging consequences for infected and affected people. One fundamental question that is relevant to the current situation is: "Who are we?" Humans are animals, there is one biology, one health and one welfare and many human-centred actions are damaging the world (Monath et al 2010, García et al 2016, Tarazona et al 2020, Fox 2020). "We" can be considered to mean all sentient beings and not just Homo sapiens (Broom and Johnson 2019). The human attitude that there can be actions for short-term gain without considering the consequences for all life must not continue.

2. Contacts with other animals and pandemic avoidance. The key point made by W\&F -that human behaviour is responsible for diseases jumping from non-human species to humans -- is also made by Gibb et al (2020) and by Petrovan et al (2020), who list 161 ways to reduce the risk of the next pandemic of zoonotic origin. Whilst only a few of these measures -- those for reducing inter-species contact where there might be pathogens originating in wild animals -- will be relevant in every case, the eight measures listed here are of general international relevance. (Some of these proposals are discussed in Lancet Editorial 2020.)

2.1. Trade in some wildlife species, such as bats, can be banned and there should be strict hygiene checks and, for both live animals and fresh carcasses, species separation during transport and trade.

2.2. All trade in animal species or products that are deemed to be high risk for pathogen transmission should be banned or licensed so that stricter hygiene and health checks can be implemented.

2.3. Risks from livestock farming should be reduced by use of protective clothing, by training farm workers, by controlling visitor and vehicle access, by separating livestock from wild animals, and by protecting food and water from contamination. 
2.4. The density of animals and their management on farms and during transport should be regulated to improve their welfare and hence immune systems so that disease and shedding of pathogens is reduced.

2.5. International transport of live farmed animals should be regulated so that detailed health checks are enforced.

2.6. Areas with high biodiversity should be preserved, and if changes in land use -- such as any degree of deforestation or mining -- are proposed, the risks of displacement or high levels of stress and inadvertent contact with livestock and people by possible pathogen carriers should always be evaluated.

2.7. Indigenous peoples and local communities should be integrated into early warning systems of disease emergence and encouraged to switch to activities unlikely to lead to zoonosis, such as lower-risk hunting.

2.8. Alternatives to animal products, especially high-risk products, should be promoted by governments and others, for example, synthetic or plant-based products instead of meat, leather, fur or traditional medicine products.

3. Antimicrobial resistance: the big problem. Although, like Anomaly (2020), I cannot agree with W\&F that the earth is a life form, I do think that the greatest problem for all life on earth at present is climate change. For humans in particular, however, the greatest problem is increasing anti-microbial resistance. The welfare of humans and other animals is clearly better if there are effective disease treatments: the deaths of humans and domestic animals have been dramatically reduced during the last hundred years by the use of antibiotic and other antimicrobial medications. But extensive misuse of antibiotics by human patients who do not understand the potential impact of their actions -- and sometimes also by medical practitioners or pharmacists wanting to please clients or to sell products -- has been the major cause of the accelerated development of bacterial strains resistant to some or all antibiotics. Examples of immoral and harmful actions include the demand for antibiotics when the disease is viral, hence not treatable by antibiotics, failure to complete full courses of antibiotics once begun, and disposal of antibiotics into sewers.

A further cause of anti-microbial resistance, however, has been excessive antibiotic use in farmed animals, especially because of cramped quarters, and poor hygiene, and to accelerate growth. In the EU, overall antibiotic use in farm animals is now reducing and currently about $19 \%$ of all antibiotic treatments (Ungemach et al 2006, ECDC/EFSA/EMEA/SCENIHR 2009, Broom and Johnson 2019). The increase in antimicrobial resistance has occurred faster than new anti-microbials have been developed, with the consequence that the next widely lethal pandemic disease may well be a formerly treatable bacterial disease such as tuberculosis. Tuberculosis is again a major disease; it caused 1.6 million human deaths in 2017 (twice as many as the current number of COVID-19 deaths) with a rapidly increasing proportion caused by resistant strains (WHO 2020). Some antibiotic resistant bacteria, such as Staphylococcus aureus and Clostridioides difficile, are also carried by and cause disease in farm and other animal species (Paterson et al 2014). Cao (2020) provides evidence of spread in China.

The prevention of pandemics and the future welfare of human and other animals hence calls not only for following the medical and veterinary advice to reduce antimicrobial resistance, but also reducing human contact with farmed animals and far more responsible management of human and farmed animal effluent. 


\section{References}

Anomaly, Jonathan (2020) Cultured meat would prevent the next Covid crisis. Animal Sentience 30(5)

Broom, D.M. \& Johnson, K.G. (2019) Stress and Animal Welfare: Key Issues in the Biology of Humans and Other Animals, $2^{\text {nd }}$ edn. ( pp 230). Cham, Switzerland: Springer Nature.

Cao, D. (2020) Global risks of intensive farming and the wildlife trade. Animal Sentience, $30(2)$

ECDC/EFSA/EMEA/SCENIHR (2009) www.ema.europa.eu.

Fox, M.W. (2020) One planet, one health. Animal Sentience 30(6).

García Pinillos, R., Appleby, M., Manteca, X., Scott-Park, F., Smith, C. \& Velarde, A. (2016) One welfare - a platform for improving human and animal welfare. Veterinary Record, 179, 412.

Gibb, R., Redding, D. W., Chin, K.Q., Donelly, C.A., Blackburn, T.M., Newbold, T. \& Jones, K.E. (2020) Zoonotic host diversity increases in human-dominated ecosystems. Nature, 584, 398-402.

Lancet Editorial (2020). Zoonoses: beyond the human-animal-environment interface. Lancet 396(10243), p1. doi.org/10.1016/S0140-6736(20)31486-0

Monath, T.P., Kahn, L.H. \& Kaplan, B. (2010) One health perspective. ILAR Journal, 51,193198.

Paterson, G.K., Harrison, E.M. \& Holmes, M.A. (2014) The emergence of mecC methicillinresistant Staphylococcus aureus. Trends in Microbiology, 22, 42-47.

Petrovan, S.O., Aldridge, D.C., Bartlett, H., Bladon, A.J., Booth, H., Broad, S., Broom, D.M., Burgess, N., Cleaveland, S., Cunningham, A.A., Ferri, M., Hinsley, A., Hua, F., Hughes, A.C., Jones, K., Kelly, M., Mayes, G., Radakovic, M., Ugwu, C.A., Uddin, N., Verissimo, D., Walzer, C., White, T.B., Wood, J. \& Sutherland, W.J. Post COVID-19: a solution scan of options for preventing future zoonotic epidemics. OSF 2020. doi 10.17605/OSF.IO/5JX3G

Tarazona, A.M., Ceballos, M.C. \& Broom, D.M. (2020) Human relationships with domestic and other animals: one health, one welfare, one biology. Animals, 10, 43; (pp. 23)

Ungemach, F.R., Müller-Bahrdt, D. \& Abraham, G. (2006) Guidelines for prudent use of antimicrobials and their implications on antibiotic usage in veterinary medicine. International Journal of Medical Microbiology, 296, 33-38.

Wiebers, D.O. \& Feigin, V.L. (2020a) What the COVID-19 crisis is telling humanity. Neuroepidemiology, 54, 283-286.

Wiebers, D.O. \& Feigin, V.L. (2020b) What the COVID-19 crisis is telling humanity. Animal Sentience 30 (1).

WHO (2020) World Health Organization. who.int. 